\title{
Mutation of outer-shell residues modulates metal ion co-ordination strength in a metalloenzyme
}

\author{
Jee-Loon F00*, Colin J. JACKSON $\uparrow$, Paul D. CARR* , Hye-Kyung KIM* , Gerhard SCHENK $\ddagger$, Lawrence R. GAHAN $\ddagger$ and \\ David L. OLLIS*1 \\ *Research School of Chemistry, Australian National University, Australian Capital Territory 0200, Australia, † Institut de Biologie Structurale, Centre National de la Recherche \\ Scientifique, Grenoble 38027, France, and $\$$ School of Chemistry and Molecular Biosciences, University of Queensland, St Lucia, Queensland 4072, Australia
}

\begin{abstract}
The metal ion co-ordination sites of many metalloproteins have been characterized by a variety of spectroscopic techniques and small-molecule model systems, revealing many important insights into the structural determinants of metal ion co-ordination. However, our understanding of this fundamentally and practically important phenomenon remains frustratingly simplistic; in many proteins it is essentially impossible to predict metal ion specificity and the effects of remote 'outer-shell' residues on metal ion co-ordination strength are also poorly defined. This is exemplified by our inability to explain why metalloenzymes with identical metal ion co-ordination spheres, such as the closely related orthologues of bacterial PTE (phosphotriesterase) from Agrobacterium radiobacter and Pseudomonas diminuta, display different metal ion specificity and co-ordination strength. In the present study, we present a series of PTE variants that all possess identical metal ion co-ordination spheres, yet display
\end{abstract}

large differences in their metal ion co-ordination strength. Using measurement of the rates of metal ion dissociation from the active site alongside analysis of structural data obtained through X-ray crystallography, we show that 'outer-shell' residues provide essential support for the metal ion ligands, in effect buttressing them in their optimal orientation. Remote mutations appear to modulate metal ion interactions by increasing or decreasing the stabilizing effects of these networks. The present study therefore provides a description of how the greater protein fold can be modified to 'tune' the strength of metal ion co-ordination and metal ion specificity, as well as reinforcing the concept of proteins as ensembles of conformational states with unique structures and biochemical properties.

Key words: directed evolution, metal ion binding, metal ion co-ordination, phosphotriesterase (PTE).

\section{INTRODUCTION}

Metals are an essential constituent of about one-third of all proteins [1]. They can be bound to proteins in a variety of ways, from being part of a cofactor, such as a haem group, to being directly co-ordinated by amino acid side chains. A wide variety of metal ion co-ordination sites have been described in the literature, which differ in both co-ordination number and geometry $[2,3]$. In some proteins the metal ions are bound tightly, whereas in others the function requires only a weak interaction. This raises the question of what determines how metal ions interact with proteins. What are the structural determinants for a tight metalion-binding site and how can binding strength be modified to allow the exchange of metal ions that is sometimes required for function?

The nature and location of co-ordinating groups has a major influence on the type of metal ions that can be bound, the strength of the interaction between the protein and metal ions, the kinetic properties of metal ion binding, and the dissociation and the functional properties of the protein. However, the influence of the protein on bound metal ions has been shown to extend beyond the primary co-ordination sphere. For example, the metal ion cofactor requirement for EcoRV was changed from $\mathrm{Mg}^{2+}$ to $\mathrm{Mn}^{2+}$ by a single amino acid change in the second co-ordination shell [4]. In the binuclear metallo-phosphodiesterase GpdQ [5,6], it has recently been demonstrated that histidine residues in the second co-ordination sphere regulate the binding of metal ions in the $\beta$ site by influencing the co-ordination environment through a network of hydrogen bonds [7]. Additionally, residue changes removed from the metal-ion-binding sites of troponin- $\mathrm{C}$ have been shown to have significant effects on calcium-ion-binding affinities [8,9].

In the present study we have focused on the metal ion coordination of variants of bacterial metallo-PTEs (phosphotriesterases), including the naturally occurring variants from Agrobacterium radiobacter (arPTE) [10] and Pseudomonas diminuta (pdPTE) [11], which differ by only 28 out of 341 amino acids and have almost identical structures [rmsd (root-meansquare deviation) of $0.38 \AA ; 1 \AA=0.1 \mathrm{~nm}$ ] [12]. The PTEs have attracted considerable attention because of their highly efficient catalysis of the hydrolysis of the pesticide EPO (paraoxon; diethyl 4-nitrophenyl phosphate) $[13,14]$, as well as their promiscuous catalytic activity towards other pesticides and structurally related organophosphate chemical warfare nerve agents [10,15-21].

The active sites of the PTEs are comprised of two adjacent metal ions co-ordinated by four conserved histidine residues, an aspartic acid and a carboxylated lysine (Figure 1) [12,22]. The PTEs natively contain one $\mathrm{Zn}$ metal ion and one Fe metal ion in hetero-binuclear active sites [23,24], although much of their characterization has been undertaken with active sites either reconstituted with various metal ions in vitro or manipulated in vivo through overexpression in the presence of excess metal ions [12,24-29]. The PTEs are active with many divalent transition metal ions, although there are considerable differences in the activities with, and binding and dissociation of, different metal ions. For example, $\mathrm{Co}^{2+}$-substituted PTEs are more active than $\mathrm{Zn}^{2+}$-substituted PTEs, and it is known that $\mathrm{Zn}^{2+}$ is more tightly

Abbreviations used: arPTE, Agrobacterium radiobacter phosphotriesterase; EPO, paraoxon (diethyl 4-nitrophenyl phosphate); EPO-OMe, diethyl 4methoxyphenyl phosphate; pdPTE, Pseudomonas diminuta phosphotriesterase; PTE, phosphotriesterase.

1 To whom correspondence should be addressed (email ollis@rsc.anu.edu.au). 


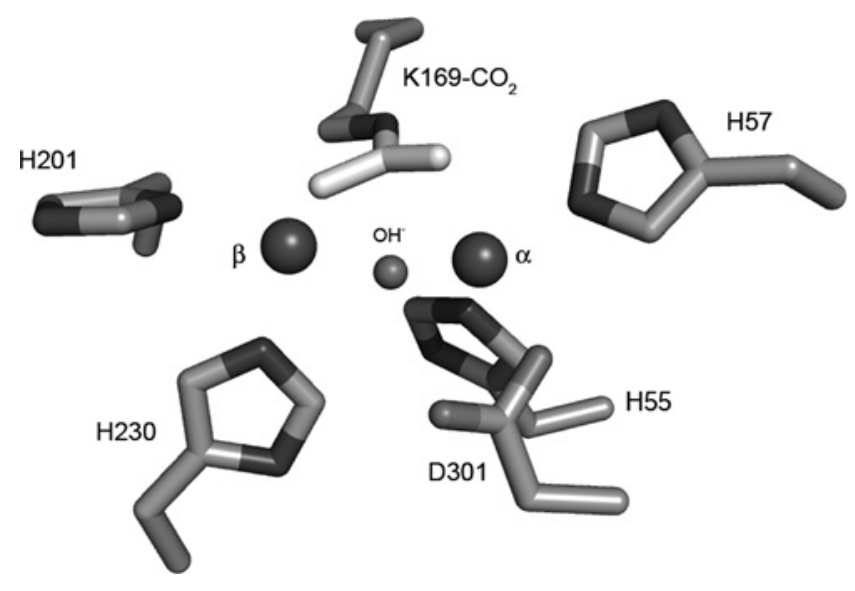

Figure 1 Structure of the metal centre of arPTE and pdPTE

co-ordinated at the active site than $\mathrm{Co}^{2+}[25,27]$. The formation of the metal-co-ordinated active site of $p d$ PTE has been studied previously [27,30]. The relationship between the carbamate bridge and the metal ions is synergistic; the metal ions need the carbamate functionality to bind in the active site and the carbamate group is stable only if it is bound to the metal ions. The assembly process of the active site was determined to be limited by the formation of the carboxylated lysine residue and the metal ions were found to add in pairs in a highly co-operative fashion [27].

We have recently characterized an arPTE variant with eight remote mutations (arPTE 8M; G60A, A80V, R118Q, K185R, Q206P, D208G, I260T and G273S) that exhibits an altered conformational distribution, in which a greater proportion of molecules in any population exist in a more 'open' configuration [14]. We were interested in determining what effect this change in the conformational distribution of the enzyme would have on the tightness of metal ion co-ordination and whether it would provide new insights into the effects of remote mutations on innershell metal ion co-ordination spheres. Thus in the present study the metal ion co-ordinating properties and structural variations of $p d \mathrm{PTE}$, arPTE and arPTE $8 \mathrm{M}$, which all have identical inner-shells, were examined. Kinetic studies were performed to determine the rate of metal ion dissociation from the PTEs. The structures of metal-ion-bound forms of the various proteins were analysed and thermal parameters examined for evidence of peptide motion in the higher co-ordination shells that might facilitate metal ion dissociation.

\section{EXPERIMENTAL}

The strains, plasmids and chemicals used, the construction of the single-site mutants, the preparation of PTEs and protein crystallization are described in the Supplementary Methods section at http://www.BiochemJ.org/bj/429/bj4290313add.htm.

\section{Metal ion reconstitution of arPTE 8M}

pdPTE or $\operatorname{arPTE} 8 \mathrm{M}(1 \mathrm{mg} / \mathrm{ml})$ in $20 \mathrm{mM}$ Hepes (pH 7.0) was incubated at $4{ }^{\circ} \mathrm{C}$ for $24 \mathrm{~h}$ in a solution with $5 \mathrm{mM}$ each of EDTA, 1,10-phenanthroline, 2,6-pyridine dicarboxylate, 8-hydroxyquinoline-5-sulfonic acid and 2-mercaptoethanol. The chelators were removed by passing the mixture through an Econo-Pac 10DG gel-filtration column (Bio-Rad Laboratories) that was equilibrated with Chelex-treated $50 \mathrm{mM}$ Tris/ $\mathrm{HCl}(\mathrm{pH} 8.5)$. The apoenzymes were reconstituted with freshly prepared $1 \mathrm{mM}$ of
$\mathrm{ZnCl}_{2}$ or $\mathrm{CoCl}_{2}$ in the presence of $50 \mathrm{mM} \mathrm{NaHCO}$ and incubated for $48 \mathrm{~h}$ at $4{ }^{\circ} \mathrm{C}$.

\section{Specific activity measurements of PTEs}

The specific activities of the PTEs were measured in $50 \mathrm{mM}$ Tris/ $\mathrm{HCl}$ (pH 8.5), $75 \mathrm{mM} \mathrm{KCl}$ and $0.1 \mathrm{mg} / \mathrm{ml} \mathrm{BSA}$ with $200 \mu \mathrm{M}$ of EPO. The rate of hydrolysis of EPO was monitored by the release of 4-nitrophenolate $\left(\varepsilon_{405}=18000 \mathrm{M}^{-1} \cdot \mathrm{cm}^{-1}\right)$ at $405 \mathrm{~nm}$ on a $96-$ well microplate $\mathrm{UV}-$ visible spectrometer.

\section{Determination of the rate of activity loss of arPTE and pdPTE}

Proteins were diluted to approx. $0.2 \mathrm{nM}$ (>50000-fold dilution) in $100 \mathrm{mM}$ Tris/ $\mathrm{HCl}(\mathrm{pH} 8.5), 150 \mathrm{mM} \mathrm{KCl}$ and $1 \mathrm{mg} / \mathrm{ml} \mathrm{BSA}$ at $0^{\circ} \mathrm{C}$ and $18^{\circ} \mathrm{C}$. Control samples containing $1 \mathrm{mM} \mathrm{CoCl}_{2}$ (or $\mathrm{ZnCl}_{2}$ for $\mathrm{Zn}$-reconstituted arPTE $8 \mathrm{M}$ ) were run in parallel. At regular time intervals, the specific activities of the samples were determined by monitoring the rate of release of 4-nitrophenol from $200 \mu \mathrm{M}$ EPO at $405 \mathrm{~nm}\left(\varepsilon_{405}=18000 \mathrm{M}^{-1} \cdot \mathrm{cm}^{-1}\right)$ on a 96 -well microplate UV-visible spectrometer. Determination of the effect of EPO-OMe (diethyl 4-methoxyphenyl phosphate) and diethyl phosphate on the rate of activity loss of arPTE $8 \mathrm{M}$ was performed similarly with $2 \mathrm{mM}$ EPO-OMe or diethyl phosphate added to the protein samples. All measurements were performed in duplicate.

The data for reconstituted arPTE $8 \mathrm{M}$ and wild-type $p d \mathrm{PTE}$ were fitted to the first-order reaction, eqn (1), using the curvefitting software KaleidaGraph:

$V=V_{0} e^{-k t}$

where $t$ is reaction time, $V$ is velocity at time $t, V_{0}$ is the initial velocity and $k$ is the first-order rate constant.

The activity decay of arPTE $8 \mathrm{M}$ prior to metal ion reconstitution consists of two concurrent first-order processes and was fitted to eqn (2) using the curve-fitting software KaleidaGraph:

$V=V_{01} e^{-k_{1} t}+V_{02} e^{-k_{2} t}$

where $t$ is reaction time, $V$ is the observed velocity at time $t, V_{01}$ and $V_{02}$ are the initial velocities of the two concurrent first-order processes and $k_{1}$ and $k_{2}$ are the respective first-order rate constants.

\section{Reactivation of aged protein}

Proteins were aged by incubating the enzymes in metal-ion-free buffer at $0^{\circ} \mathrm{C}$ and $18^{\circ} \mathrm{C}$ for various durations. The activities were determined by measuring the rate of production of 4-nitrophenol from $200 \mu \mathrm{M}$ EPO at $405 \mathrm{~nm}\left(\varepsilon_{405}=18000 \mathrm{M}^{-1} \cdot \mathrm{cm}^{-1}\right)$ on a 96-well microplate UV-visible spectrometer. $\mathrm{CoCl}_{2}$ (1 mM) was added to the aged enzymes and the amount of activity recovered from the enzymes after 2 min of incubation was determined. The $\mathrm{CoCl}_{2}$-supplemented samples were incubated at $4{ }^{\circ} \mathrm{C}$ and activities were similarly measured after $24 \mathrm{~h}$ to determine the extent of reactivation. No further increase in activity was observed for all of the enzymes upon longer incubation.

\section{X-ray data collection and structural analysis}

No new crystallographic structures were collected for the present study; the arPTE 8M crystal structures used in the present study were from X-ray data collected and refined in our previous work (PDB codes 3A3W and 3A3X; Supplementary Table S1 
Table 1 First-order rate constants determined for the loss of specific activity (200 $\mu \mathrm{M}$ EPO) of arPTE 8M and pdPTE at $18^{\circ} \mathrm{C}$

The arPTE $8 \mathrm{M}$ values are consistent with concurrent dissociation of $\mathrm{Zn}^{2+}$ and $\mathrm{Co}^{2+}$, whereas the $p d \mathrm{PTE}$ values are consistent with dissociation of $\mathrm{Co}^{2+}$

\begin{tabular}{ll}
\hline Enzyme & Rate constants $\left(\mathrm{s}^{-1}\right)$ \\
\hline arPTE 8M & \\
Co $^{2+}$-reconstituted arPTE 8M & $3.0 \times 10^{-5} ; 3.6 \times 10^{-4}$ \\
Zn $^{2+}$-reconstituted arPTE 8M & $3.5 \times 10^{-4}$ \\
pdPTE & $1.2 \times 10^{-5}$ \\
Co $^{2+}$-reconstituted pdPTE & $1.3 \times 10^{-4}$ \\
Zn ${ }^{2+}$-reconstituted pdPTE & $5.0 \times 10^{-5}$ \\
H254R pdPTE & $9.5 \times 10^{-6}$
\end{tabular}

at http://www.BiochemJ.org/bj/429/bj4290313add.htm) [14]. In brief, the crystals were serially transferred into a cryoprotecting solution consisting of $40 \%$ PEG [poly(ethylene glycol)] 3350 and $0.2 \mathrm{M} \mathrm{NaNO}_{3}$ at $4{ }^{\circ} \mathrm{C}$ and stored for $12 \mathrm{~h}$ or $72 \mathrm{~h}$. A crystal that was stored for $72 \mathrm{~h}$ was subsequently transferred into a cryoprotecting solution of the same composition supplemented with $2 \mathrm{mM}$ EPO-OMe and soaked for $90 \mathrm{~min}$; no soaking with EPO-OMe was performed with the crystals that were stored for $12 \mathrm{~h}$. The crystals were flash-cooled to $100 \mathrm{~K}$ in a cryogenic nitrogen gas stream. Diffraction data for the crystals were collected at the Stanford Synchrotron Radiation Laboratory (Menlo Park, CA, U.S.A.) as described previously [24]. Refinement was performed as described previously [14]. Occupancies of metal ions and ligands were adjusted until the $B$-factors of the metal ions and ligands were comparable with those of the interacting residues. Absolute electron densities at the metal ion sites were determined with COOT [31].

The PDB codes for the wild-type arPTE and $p d \mathrm{PTE}$ structures used are 2D2J [32] and 1HZY [26]. An alternative conformation was added to $\mathrm{Ser}^{203}$ of the published wild-type arPTE structure based on residual positive density. The average main chain $B$-factors were calculated with Baverage, as implemented in the CCP4 suite of programs [33]. Rendered images of protein structures were generated with PyMOL (DeLano Scientific; http://www.pymol.org).

\section{RESULTS AND DISCUSSION}

\section{Rates of metal ion dissociation in PTE variants}

Shim and Raushel [27] have demonstrated and characterized spontaneous metal ion dissociation from the active site of $p d$ PTE. In the present study, we have extended this analysis to the natural arPTE orthologue and an arPTE $8 \mathrm{M}$ variant obtained via laboratory evolution [14]. All three enzymes have identical metal ion co-ordination sites, but differ at amino acid positions in the second and third co-ordination shells. As shown in Figure 2, the rates of decay of the PTE activity at $18^{\circ} \mathrm{C}$, using the enzymes as purified from $\mathrm{Co}^{2+}$-supplemented expression medium, differed markedly. The activity of arPTE did not significantly decrease over $400 \mathrm{~min}$, whereas $p d \mathrm{PTE}$ and arPTE $8 \mathrm{M}$ lost activity rapidly over the same time-course, consistent with our observation that addition of excess exogenous metal ions to the storage buffer was essential to prevent activity in $p d \mathrm{PTE}$ and $\operatorname{arPTE} 8 \mathrm{M}$, but not arPTE. Whereas the rate of activity decay in $p d \mathrm{PTE}$ was consistent with a first-order process, the activity decay of arPTE $8 \mathrm{M}$ was biphasic and consistent with concomitant first-order loss of two metal ions with different dissociation constants $\left(3.0 \times 10^{-5}\right.$ and $3.6 \times 10^{-4} \mathrm{~s}^{-1}$; Table 1 ).

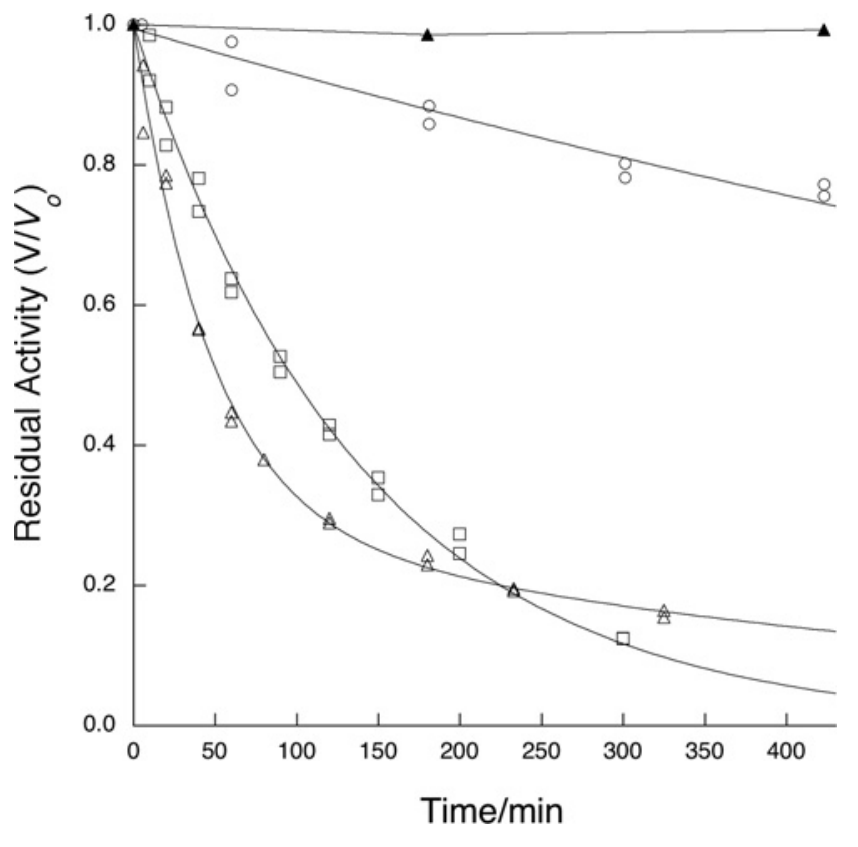

Figure 2 Activity decay at $18^{\circ} \mathrm{C}$ of PTEs

Activity decays are shown for wild-type $\operatorname{arPTE}(\mathbf{\Delta})$, pdPTE H254R (O), wild-type pdPTE ( $\square$ ) and $\operatorname{arPTE} 8 \mathrm{M}(\Delta)$. The specific activities $(V)$ of the enzymes as a fraction of the initial specific activities $\left(V_{0}\right)$ are plotted against time. Despite having identical metal ion co-ordination sites, the rates of activity loss are different between the four PTEs. Wild-type arPTE shows negligible activity loss over approx. 400 min. Wild-type pdPTE and its H254R mutant exhibit first-order activity decay, whereas the loss in activity of arPTE $8 \mathrm{M}$ resembles two concurrent first-order processes. The data points are fitted to eqns (1) or (2) and the fitted curves are shown as continuous lines.

To further investigate the metal ion dissociation process, we reconstituted apoenzyme forms of $\operatorname{arPTE} 8 \mathrm{M}$ and pdPTE with either $\mathrm{Co}^{2+}$ or $\mathrm{Zn}^{2+}$. The activity decay processes of $\mathrm{Co}^{2+}$ - and $\mathrm{Zn}^{2+}$-reconstituted arPTE $8 \mathrm{M}$ obeyed first-order rate laws, with activity decay of the $\mathrm{Zn}^{2+}$ form occurring approx. 10-fold slower than the $\mathrm{Co}^{2+}$ form (Table 1). These respective rates are in good agreement with the two rates obtained from the 'as purified' sample, supporting the conclusion that the biphasic decay of this sample is a result of concomitant rapid loss of $\mathrm{Co}^{2+}$ and slower dissociation of $\mathrm{Zn}^{2+}$. The activity decay rate constants of $\mathrm{Co}^{2+}$ reconstituted $p d \mathrm{PTE}$ and 'as purified' $p d \mathrm{PTE}$ were essentially identical, suggesting that $\mathrm{Co}^{2+}$ was the main metal ion dissociating from the active site in the 'as purified' sample. A slower rate of activity decay was observed from the $\mathrm{Zn}^{2+}$-reconstituted $p d \mathrm{PTE}$ sample, suggesting tighter association of $\mathrm{Zn}^{2+}$ to the enzyme than $\mathrm{Co}^{2+}$, consistent with previous work [27]. These results are significant in that they demonstrate that the identical metal ion co-ordination sites of arPTE and $p d$ PTE have vastly different coordination strengths for different metal ions, and that mutations remote from these co-ordination sites, as seen in arPTE 8M, can switch the character of these binuclear sites from 'tight' (arPTE) to 'loose' ( $p d \mathrm{PTE})$.

\section{Reactivation of aged PTE variants}

Having characterized the process of metal ion dissociation from the three PTE variants, we investigated the processes by which their activity could be reconstituted. After $p d$ PTE and arPTE $8 \mathrm{M}$ were aged at $0^{\circ} \mathrm{C}$ and $18^{\circ} \mathrm{C}$, excess exogenous metal ions were added to the enzymes (Table 2). When aged at $0{ }^{\circ} \mathrm{C}$ for $24 \mathrm{~h}$ (giving $1 \%$ residual activity for arPTE $8 \mathrm{M}$ and $36 \%$ residual activity for 


\section{Table 2 Reactivation of aged $\mathrm{Co}^{2+}$-reconstituted arPTE 8M and pdPTE}

After aging of $\mathrm{Co}^{2+}$-reconstituted arPTE $8 \mathrm{M}$ and $p d \mathrm{PTE}$ for various length of times at different temperatures, $1 \mathrm{mM} \mathrm{CoCl} 2$ was added to study the reactivation of the aged enzymes. The 'After reactivation' column shows the activity after a 2 min incubation of the aged PTEs with $1 \mathrm{mM} \mathrm{CoCl}$.

\begin{tabular}{|c|c|c|c|c|c|}
\hline \multirow[b]{2}{*}{ Enzyme } & \multirow[b]{2}{*}{ Aging temperature $\left({ }^{\circ} \mathrm{C}\right)$} & \multirow[b]{2}{*}{ Aging time (h) } & \multicolumn{3}{|l|}{ Residual activity (\%) } \\
\hline & & & Before reactivation & After reactivation & After incubation at $4^{\circ} \mathrm{C}$ for $24 \mathrm{~h}$ \\
\hline $\mathrm{Co}^{2+}-$ arPTE $8 \mathrm{M}$ & 0 & 24 & 1 & 88 & 88 \\
\hline $\mathrm{Co}^{2+}$-arPTE $8 \mathrm{M}$ & 18 & 3 & 3 & 11 & 32 \\
\hline $\mathrm{Co}^{2+}-p d \mathrm{PTE}$ & 0 & 24 & 36 & 60 & 86 \\
\hline $\mathrm{Co}^{2+}-p d \mathrm{PTE}$ & 18 & 3 & 6 & 11 & 52 \\
\hline
\end{tabular}

$p d \mathrm{PTE}$ ), almost $90 \%$ of the initial activity of arPTE $8 \mathrm{M}$ could be restored within $2 \mathrm{~min}$ of addition of $1 \mathrm{mM} \mathrm{CoCl}$, whereas only $24 \%$ of the initial activity of $p d \mathrm{PTE}$ (from $36 \%$ to $60 \%$ ) could be restored within $2 \mathrm{~min}$ of addition of $1 \mathrm{mM} \mathrm{CoCl}$, although further incubation at $4{ }^{\circ} \mathrm{C}$ for $24 \mathrm{~h}$ results in a recovery of $86 \%$ of the original activity. In contrast, when the proteins were aged at $18^{\circ} \mathrm{C}$ for $3 \mathrm{~h}$ (giving $3 \%$ residual activity for $\operatorname{arPTE} 8 \mathrm{M}$ and $6 \%$ residual activity for $p d \mathrm{PTE}$ ), both enzymes regained only $11 \%$ of their initial activity after $2 \mathrm{~min}$ incubation with $1 \mathrm{mM} \mathrm{CoCl}$ and further incubation at $4{ }^{\circ} \mathrm{C}$ for $24 \mathrm{~h}$ resulted in the recovery of $32 \%$ of the original activity of $\operatorname{arPTE} 8 \mathrm{M}$ and $52 \%$ of the original activity of $p d$ PTE.

It is important that we highlight two important results from other groups before we analyse the above results. First, Shim and Raushel [27] have demonstrated the importance of the carboxylation of Lys ${ }^{169}$ for formation of the binuclear metal ion centre, showing that loss of the carbamate group decreased the rate of formation of the metal ion centre by several orders of magnitude. Secondly, Roodveldt and Tawfik [35] have shown that the apoenzyme is highly unstable and rapidly undergoes irreversible thermal denaturation. Thus inactivation will proceed through at least three steps: (i) loss of metal ions, (ii) loss of the carbamate group, and (iii) irreversible denaturation. All of these effects are apparent in the present results. For arPTE $8 \mathrm{M}$ aged at $0{ }^{\circ} \mathrm{C}$ for $24 \mathrm{~h}$, activity can be almost fully restored within 2 min upon incubation with $\mathrm{Co}^{2+}$ metal ions, suggesting that although sufficient metal ions were lost, to completely inactivate the enzyme, the carbamate group remained intact. This would be consistent with the loss of one metal ion, disrupting activity, while the second metal ion could be retained to stabilize the carbamate group. In contrast, for $p d \mathrm{PTE}$ after rapid restoration of $24 \%$ of activity, within $2 \mathrm{~min}$, it took $24 \mathrm{~h}$ incubation with $1 \mathrm{mM} \mathrm{Co}^{2+}$ at $4{ }^{\circ} \mathrm{C}$ to restore a further $26 \%$ of its activity ( $86 \%$ total), consistent with a mixed population in which $24 \%$ of the molecules had retained the carbamate group, allowing rapid reconstitution, and at least $26 \%$ had lost both metal ions and the carbamate group and required longer incubation to reach the functional binuclear state. This suggests that, although the initial loss of one metal ion is more rapid in arPTE $8 \mathrm{M}$, full dissociation of both metal ions is faster in $p d \mathrm{PTE}$. When the enzymes were aged at $18^{\circ} \mathrm{C}$, reactivation to the levels of the enzymes aged at $4{ }^{\circ} \mathrm{C}$ was impossible, even after $24 \mathrm{~h}$, suggesting that a significant proportion of the sample had progressed to the third stage of inactivation and undergone irreversible denaturation.

\section{Characterizing the order of metal ion dissociation}

The results described above suggest that, unlike its co-operative formation, the binuclear active site of the PTEs decomposes in a stepwise fashion, in which a loosely co-ordinated metal

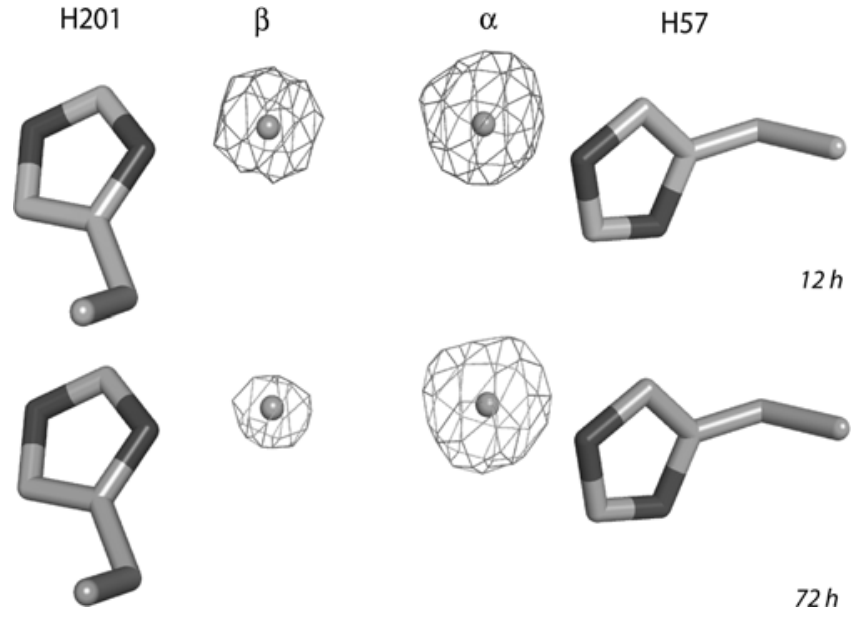

Figure 3 Metal ion occupancy at the $\beta$-metal site of arPTE 8M

The $2 \mathrm{~m} F_{0}-D F_{c}$ maps contoured at $5 \sigma$ for arPTE $8 \mathrm{M}$ crystals collected after $12 \mathrm{~h}$ and $72 \mathrm{~h}$ of soaking in metal-free cryoprotectant are shown. The occupancy at the $\beta$-site is significantly reduced with increasing soaking time.

Table 3 Absolute electron densities of metal ions in arPTE 8M structures obtained from crystals soaked in metal-ion-free cryoprotecting solutions for different lengths of time

\begin{tabular}{llll}
\hline & \multicolumn{2}{l}{$\begin{array}{l}\text { Absolute electron density } \\
\text { at metal sites }\left(\mathrm{e} \cdot \AA^{-3}\right)\end{array}$} & \\
\cline { 2 - 3 } Soaking time & $\beta$ & $\alpha$ & Ratio $\beta / \alpha$ \\
\hline $12 \mathrm{~h}$ & 5.12 & 8.12 & 0.63 \\
$72 \mathrm{~h}$ & 2.36 & 5.74 & 0.41 \\
\hline
\end{tabular}

ion dissociates first, followed by the second metal ion and the carbamate group. To investigate this process, we reanalysed the occupancy of active-site metal ions in crystal structures of arPTE $8 \mathrm{M}$ that have been published in a previous study (PDB codes $3 \mathrm{~A} 3 \mathrm{X}$ and $3 \mathrm{~A} 3 \mathrm{~W}$ ) [14]. These crystals were stored in cryoprotecting solution in the absence of exogenous metal ions for periods of $12 \mathrm{~h}$ and $72 \mathrm{~h}$ at $4{ }^{\circ} \mathrm{C}$. In both structures, the occupancies of the $\alpha$-metal ion and carbamate functionality were essentially $100 \%$, whereas absolute electron density at the $\beta$-site relative to that of the $\alpha$-site, and thus the assumed occupancy of the $\beta$-metal ion, decreased from $90 \%$ in the $12 \mathrm{~h}$ structure to $60 \%$ in the $72 \mathrm{~h}$ structure (Figure 3 and Table 3 ). We note that the $72 \mathrm{~h}$ structure had been soaked with EPO-OMe (a substrate) for 90 min prior to data collection; to eliminate the possibility that this substrate, or the hydrolysis product diethyl phosphate, acted as a metal ion 


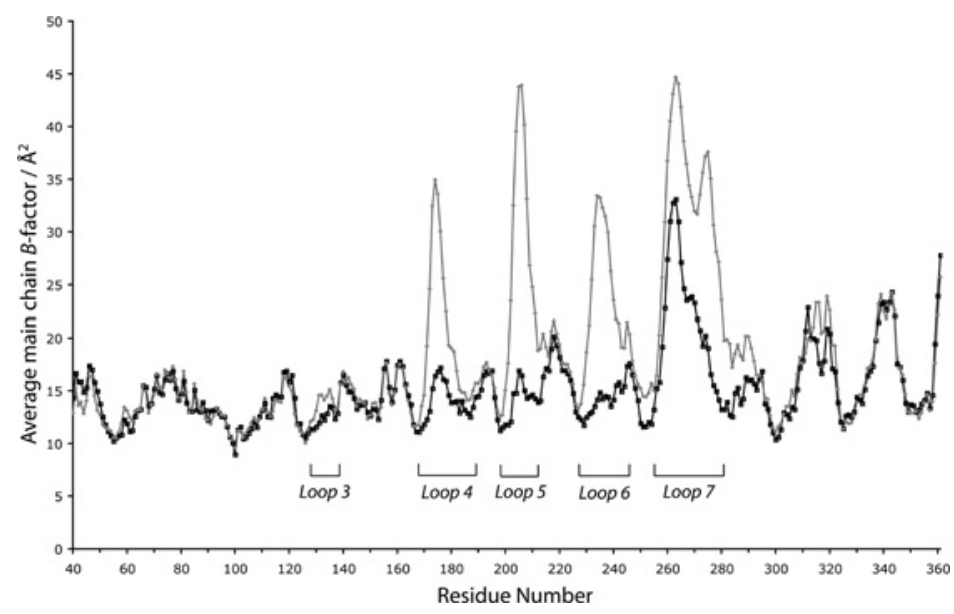

Figure 4 Main chain $B$-factor plots of wild-type (black) and arPTE 8M (grey)

Loops with markedly increased $B$-factor in arPTE 8M relative to the wild-type that are of particular interest in the present study are indicated.

chelator, the rate of activity decay was determined in the presence and absence of these compounds. No significant differences in rate of activity decay were observed in these control reactions. These results strongly suggest that the process of metal ion dissociation from the active site of the arPTE $8 \mathrm{M}$ is initiated by loss of the metal ion at the 'loose' $\beta$-site and that a significant proportion of molecules are stable at $0^{\circ} \mathrm{C}$ in a mononuclear form in which the $\alpha$-metal ion and the carbamate bridge are retained.

\section{Modulation of metal ion co-ordination strength by outer-shell mutations: the importance of conformational fluctuations}

Up to this point we have demonstrated that the naturally occurring PTE variants $a r$ PTE and $p d$ PTE have vastly different metal ion co-ordination strengths, despite identical active sites, and that this difference can be caused by as few as eight outer-shell mutations. In this section, we examine the structural effects of these outer-shell mutations and how they can modulate the strength of metal ion co-ordination. To do this, we have analysed the isotropic $B$-factors in crystal structures determined under cryogenic conditions, which reflect the accuracy of the model; in regions that are highly mobile the crystal will be frozen, with these regions adopting a variety of conformations, giving rise to high $B$-factors. The $B$-factor plots for wild-type $\operatorname{arPTE}$ and the $\operatorname{arPTE}$ $8 \mathrm{M}$ mutant (with $90 \% \beta$-metal ion occupancy) are shown in Figure 4 . There are five distinct regions with increased $B$-factors, indicative of greater conformational diversity. These regions correspond to five loops on the upper face of PTE, where the active site is located: loop 3, residues 130-135; loop 4, residues 170 190; loop 5, residues 200-210; loop 6, residues 230-245; and loop 7, residues 254-280 (Figure 5). In the present analysis we focus on the four mutations located in the surface loops that are seen to have higher $B$-factors: Q206P/D208G in loop 5 (200-210) and I260T/G273S in loop 7 (254-280). The other mutations (G60A, A80V, R119Q and K185R) are either known to be catalytically silent stabilizing mutations (A80V, R119Q, K185R) [12,36] or to affect $K_{\mathrm{m}}$ by altering the substrate-binding pocket (G60A) [37], and hence are not thought to affect conformational diversity or metal ion binding.

\section{Remote effects on $\mathrm{His}^{201}$}

The long-range effects of the Q206P and D208G mutations in loop 5 are best illustrated if we first explain how His ${ }^{201}$ is stabilized in

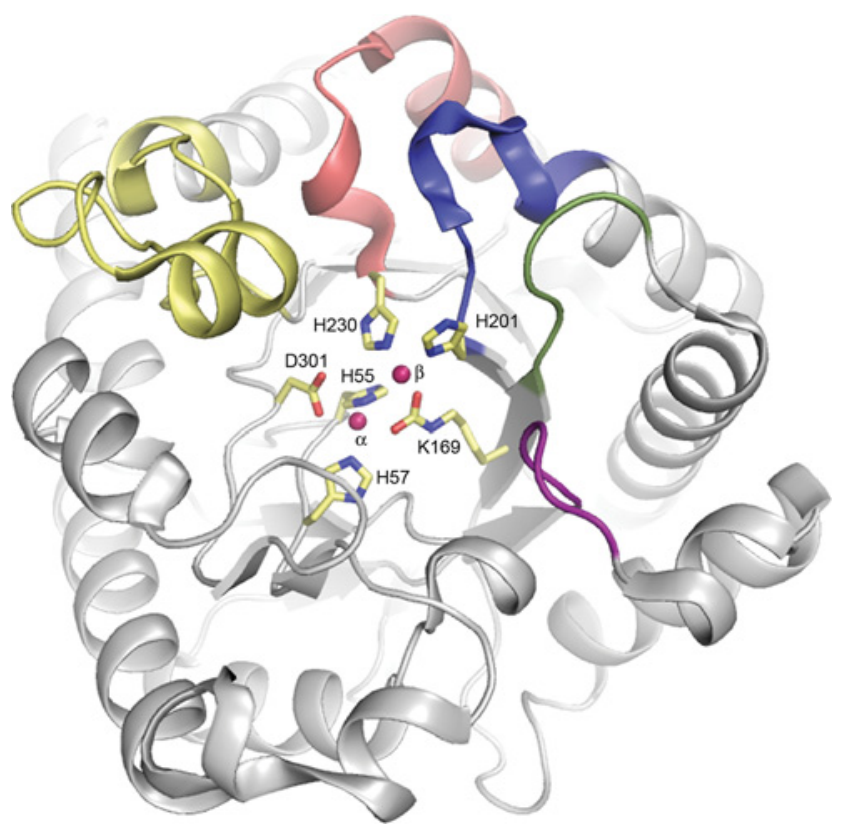

Figure 5 Loops with increased $B$-factors in arPTE 8M relative to the wildtype enzymes

Different colours are used to indicate loop 3 (purple), loop 4 (green), loop 5 (blue), loop 6 (red) and loop 7 (gold).

its co-ordinating conformation. As shown in Figure 6(a), $\mathrm{His}^{201}$ is stabilized in its ideal rotamer via edge-face $\pi-\pi$ interactions between its imidazole group and the aromatic group of $\mathrm{Phe}^{132}$ in the second shell. In wild-type $\operatorname{arPTE}, \mathrm{Phe}^{132}$ and thus His ${ }^{201}$ are supported in these conformations by $\mathrm{Thr}^{173}$ in loop 4, which is in turn supported in its conformation via an inter-loop hydrogen bond network with loop 5 , mediated by the carboxylate side chain of $\mathrm{Asp}^{208}$, the hydroxy group of $\mathrm{Thr}^{172}$ and the peptide backbones of Gly ${ }^{174}$ and $\operatorname{Ser}^{203}$ (Figure 6a). It has been shown that in $\operatorname{arPTE} 8 \mathrm{M}$ Phe ${ }^{132}$ adopts a second rotamer in which it 'flips' to a more open conformation (40\% occupancy) [14], resulting in the loss of much of the $\pi-\pi$ stacking interactions with $\mathrm{His}^{201}$, thereby reducing the stabilization of $\mathrm{His}^{201}$ in 

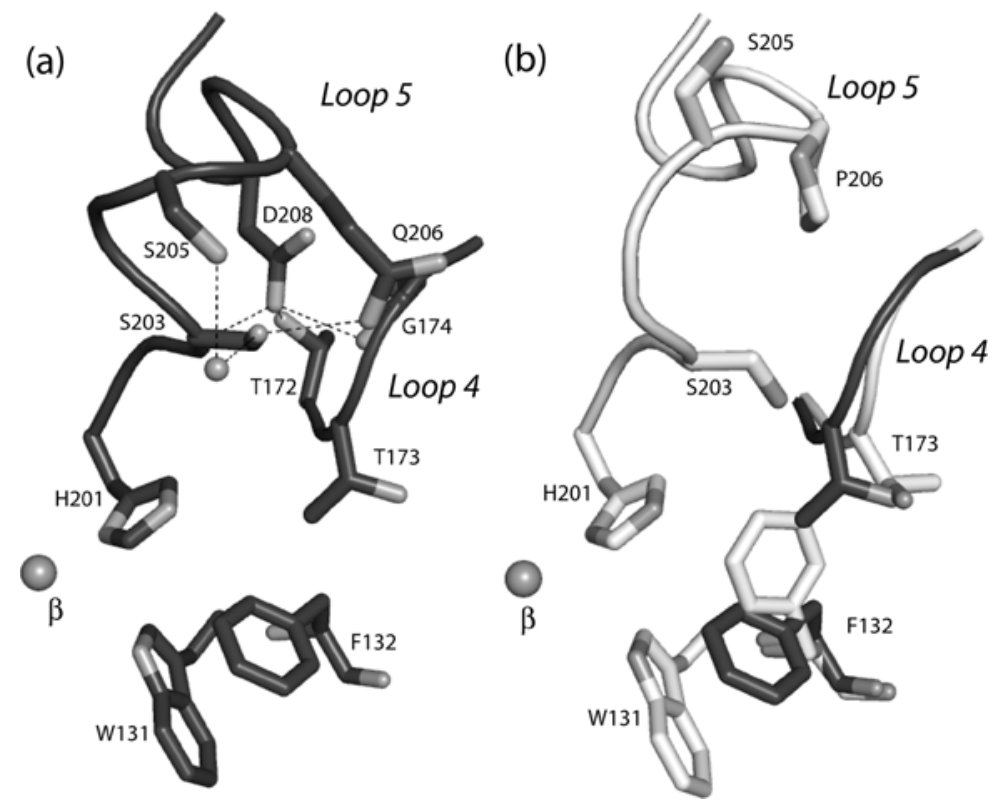

Figure 6 Influence of Q206P and D208G on metal ion co-ordinating strength

(a) Inter-loop hydrogen bonds between $\mathrm{Asp}^{208}, \mathrm{Ser}^{203}, \mathrm{Thr}^{173}$ and Gly ${ }^{174}$, and intra-loop interactions between $\mathrm{Ser}^{203}, \mathrm{Ser}^{205}$ and Gln ${ }^{206}$ in arPTE (dark grey). These hydrogen bonds are lost in arPTE 8M (white) due to Q206P and D208G mutations, as illustrated in (b). Consequently, loop 4 has more conformational lability and allows Phe ${ }^{132}$ to adopt a second rotamer that disrupts the stabilizing $\pi-\pi$ interactions with $\mathrm{His}^{201}$. The destabilization of loop 5 due to loss of intra-loop hydrogen bonds could also cause fluctuation of His ${ }^{201}$. These contribute to the weaker metal ion co-ordination of arPTE 8M.

Table 4 Loss of specific activity (200 $\mu \mathrm{M} \mathrm{EPO)}$ of arPTE mutants in metalion-free buffer after $24 \mathrm{~h}$ at $18^{\circ} \mathrm{C}$

\begin{tabular}{llrr}
\hline & \multicolumn{2}{l}{$\begin{array}{l}\text { Specific activity of arPTE } \\
\left(\mu \mathrm{M} \mathrm{s}^{-1} \cdot \mu \mathrm{M}^{-1}\right)\end{array}$} & \\
\cline { 2 - 3 } arPTE mutant & Initial & After 24 h & Residual activity after 24 $\mathrm{h}(\%)$ \\
\hline 8M & 1209 & 26 & 2 \\
Q206P & 1711 & 515 & 30 \\
D208G & 1964 & 584 & 30 \\
S203A & 1260 & 788 & 63 \\
S205A & 1029 & 677 & 66 \\
Q206A & 1789 & 1062 & 59 \\
\end{tabular}

its ideal co-ordinating geometry. This secondary conformer of $\mathrm{Phe}^{132}$ is blocked by $\mathrm{Thr}^{173}$ in wild-type $\operatorname{arPTE}$, but the Q206P and D208G mutations in arPTE 8M cause the loss of a number of intra-loop interactions in loop 5 (between $\mathrm{Ser}^{203}$, $\mathrm{Ser}^{205}$ and $\mathrm{Gln}^{203}$ ) and inter-loop interactions with loop 4 (between $\mathrm{Asp}^{208}, \mathrm{Ser}^{203}, \mathrm{Thr}^{172}$ and $\mathrm{Gly}^{174}$ ), resulting in loop 4 adopting a more open conformation and permitting $\mathrm{Phe}^{132}$ to adopt this secondary conformer (Figure 6b). To test how mutations within loop 5 can affect metal ion dissociation, we created a series of point mutants (Q206P, D208G, S203A, S205A and Q206A) (Table 4) and measured their residual activity after $24 \mathrm{~h}$ in metalion-free buffer. All mutants showed greater loss of activity after overnight incubation at $18{ }^{\circ} \mathrm{C}$ than the wild-type enzyme, although none showed the same magnitude of loss as seen in arPTE $8 \mathrm{M}$ (Table 4). We note that the alternative conformer of $\mathrm{Phe}^{132}$ is also commonly observed in pdPTE structures (PDB codes 1QW7, 2OB3, 2OQL and 3CAK) at significant occupancy (unlike in wild-type arPTE), which may partially explain the weaker metal ion co-ordination of $p d$ PTE compared with wild-type arPTE.

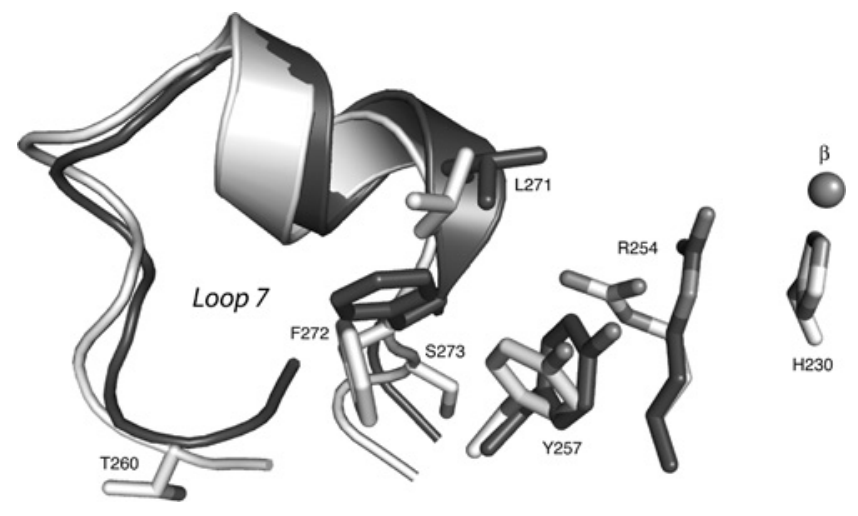

Figure 7 Remote effect of loop 7 on $\mathrm{His}^{230}$

$\mathrm{His}^{230}$ is stabilized through cation $-\pi$ interaction with $\mathrm{Arg}^{254}$. However, the conformation of loop 7 in arPTE 8M (white) is more 'open' compared with the wild-type enzyme (grey), most probably due to the I260T and G273S mutations. Thus $\mathrm{Arg}^{254}$ has additional room to adopt an alternative rotameric form, which disrupts the cation- $\pi$ interaction with $\mathrm{His}^{230}$.

\section{Remote effects on $\mathrm{His}^{230}$}

The observation that loop 5 point mutants showed slower metal ion dissociation rates than arPTE $8 \mathrm{M}$, suggests other mutations also contribute to the increased rate of metal ion loss. As with the long-range effects of D208G and Q206P on His ${ }^{201}$, remote effects of I260T and G273S on the second histidine metal ion ligand, $\mathrm{His}^{230}$, are best explained if we first describe how His ${ }^{230}$ is stabilized in wild-type arPTE. In an analogous situation to $\mathrm{Phe}^{132}$ and $\mathrm{His}^{201}$, His ${ }^{230}$ is stabilized by a second-shell residue; in this case, via a cation- $\pi$ interaction with $\operatorname{Arg}^{254}$ (Figure 7). We have shown previously that loop 7 adopts an 'open' conformation in $\operatorname{arPTE} 8 \mathrm{M}$ that is only present at very low occupancy in the wild-type enzyme [14], most likely due to the I260T and G273S 
mutations that are located at the 'hinge' region of loop 7. This more open conformation again provides room for the stabilizing residue $\left(\mathrm{Arg}^{254}\right)$ to adopt a second conformer in which the cation$\pi$ interactions with the metal ion ligand at $\mathrm{His}^{230}$ will be lost. This is consistent with the $B$-factors of $\mathrm{Arg}^{254} \operatorname{arPTE} 8 \mathrm{M}$ being significantly higher than in $\operatorname{arPTE}\left(15.7\right.$ compared with $11.9 \AA^{2}$ ) (Figure 4). pdPTE contains $\mathrm{His}^{254}$ rather than $\mathrm{Arg}^{254}$; however, $\mathrm{His}^{254}$ can still form $\pi-\pi$ interactions with $\mathrm{His}^{230}$, but the distance is greater and, at the $\mathrm{pH}$ at which the dissociation is measured ( $\mathrm{pH} 8.5$ ), His ${ }^{254}$ will be predominantly uncharged (unlike $\mathrm{Arg}^{254}$ ) thus resulting in a reduced stabilizing interaction. To test the hypothesis that $\mathrm{Arg}^{254}$ is stabilizing, relative to $\mathrm{His}^{254}$, we made a H254R mutant of pdPTE, which showed a 13-fold decrease in the rate of metal ion dissociation, confirming that this residue significantly stabilizes the metal ions in their bound state from its position in the second co-ordination sphere.

In addition to the reduced stabilizing interaction attributable to $\mathrm{Arg}^{254}$, arPTE $8 \mathrm{M}$ also exhibits a dramatic loss of hydrogenbonding interactions between loop 6, upon which His ${ }^{230}$ is located, and loops 5 and 7 . In wild-type arPTE this network involves interactions between $\mathrm{Asp}^{233}, \mathrm{Thr}^{234}, \mathrm{Asp}^{236}$ (loop 6), $\mathrm{Thr}^{202}, \mathrm{Ala}^{204}$, $\mathrm{Arg}^{207}$ (loop 5) and several structural water molecules, and $\mathrm{Asp}^{232}$, $\mathrm{Asp}^{233}, \mathrm{Asp}^{235}, \mathrm{Arg}^{275}$ and $\mathrm{Arg}^{280}$ (loop 7) (Figure 8a). However, in arPTE 8M, conformational changes to loop 5 (as a result of Q206P and D208G) and loop 7 (as a result of I260T and G273S) result in lengthening of several of these hydrogen bonds and loss of others (Figure 8b), ultimately destabilizing loop 6 and the metal ion ligand $\mathrm{His}^{230}$.

\section{Remote effects on Asp ${ }^{301}$}

We have demonstrated that the $\beta$-metal ion is the first to dissociate (Figure 3 ) and that although this process occurs more quickly in arPTE $8 \mathrm{M}$ than in $p d \mathrm{PTE}$, dissociation of the $\alpha$-metal ion, which can still stabilize the carbamate bridge, is likely to occur more quickly in $p d \mathrm{PTE}$, as evidenced by its slower, carboxylationdependent reactivation (Table 2). Three amino acid residue differences between arPTE and $p d \mathrm{PTE}$ in the vicinity of the $\alpha$-site, particularly around the metal ion ligand $\mathrm{Asp}^{301}$, may be responsible for the differences in metal ion co-ordinating strength. In $p d \mathrm{PTE}, \mathrm{Arg}^{254}, \mathrm{Tyr}^{257}$ and $\mathrm{His}^{300}$ of arPTE are replaced by $\mathrm{His}^{254}$, His ${ }^{257}$ and $\mathrm{Asn}^{300}$. As shown in Figure 9, there are more stabilizing hydrogen-bonding interactions around $\mathrm{Asp}^{301}$ in $\operatorname{arPTE}$ than $p d \mathrm{PTE}$, due to the longer side chain of $\mathrm{His}^{300}$, the additional
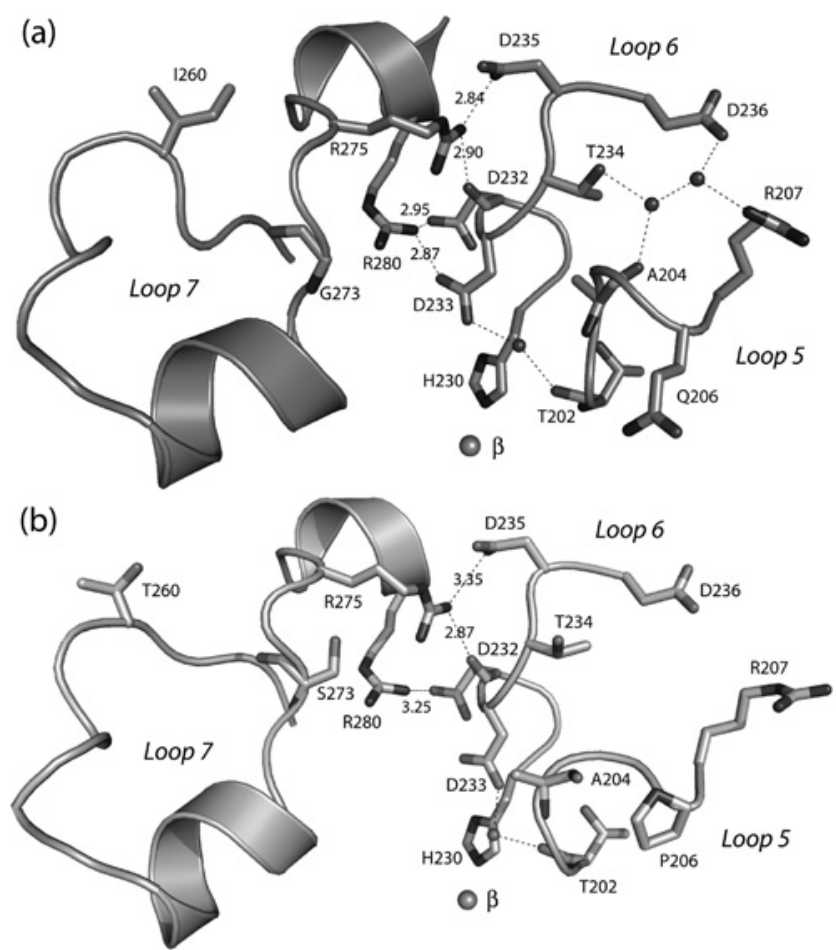

Figure 8 Changes in interaction between loops 5 and 7 in arPTE 8M

(a) The network of hydrogen bonds between loops 5, 6 and 7 in arPTE. These interactions are weakened or lost in arPTE 8M due to conformational changes as a result of the mutations Q206P, I260T and G273S, as illustrated in (b).

-NH group of $\mathrm{Arg}^{254}$ and the higher polarity of the phenolic -OH of $\mathrm{Tyr}^{257}$ in $\operatorname{arPTE}$. These differences in interaction suggest that the position of $\mathrm{Asp}^{301}$ may be less stable in pdPTE than in arPTE thus weakening the co-ordination bond between the carboxylate functionality and the $\alpha$-metal ion, resulting in faster dissociation of the $\alpha$-metal ion.

\section{Conclusions}

Many studies have established that the nature and strength of metal ion co-ordination in metalloproteins can be modulated by altering the co-ordination number, geometry and ligand types of the

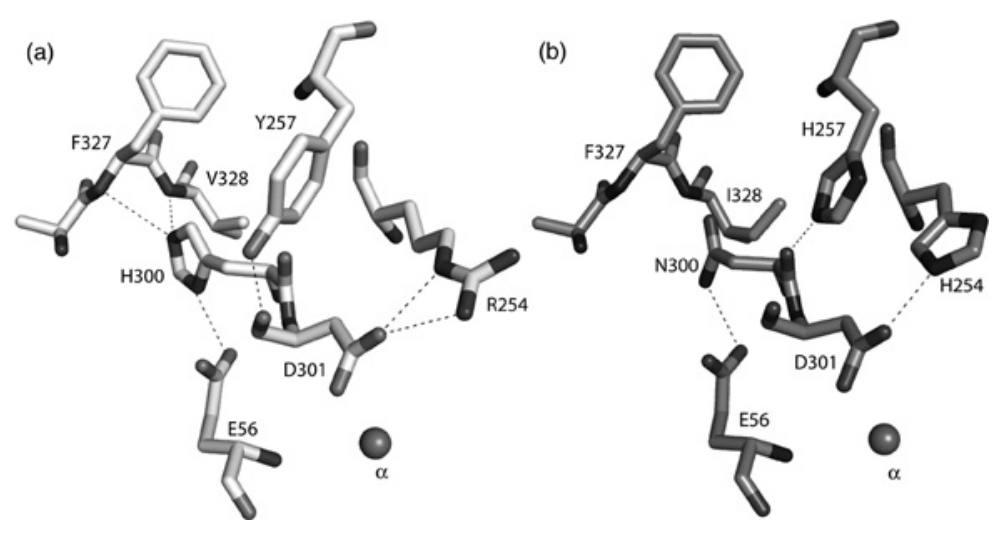

Figure 9 Differences in interactions between (a) arPTE and (b) pdPTE around Asp $p^{301}$

Replacement of $\mathrm{Arg}^{254}$, Tyrr 257 and $\mathrm{His}^{300}$ of arPTE by His ${ }^{254}$, $\mathrm{His}^{257}$ and Asn ${ }^{300}$ in pdPTE leads to a reduction in hydrogen bonding in the vicinity of Asp ${ }^{301}$, which possibly accounts for the weaker metal ion co-ordination at the $\alpha$-site of $p d P T E$. 
first co-ordination sphere [2,3,38,39]. More recently, it has been recognized that second and higher co-ordination shell amino acid residues also play critical roles in defining the metal-ion-binding characteristics and activities of metalloproteins [7,40-46]. In the present study we have shown that three homologous PTEs with identical metal ion co-ordination shells have distinct metal ion dissociation rates: the native $p d$ PTE exhibits significantly weaker metal ion interactions than native arPTE. However, eight remote mutations in the arPTE $8 \mathrm{M}$ variant can drastically weaken the strength of metal ion co-ordination at the $\beta$-metal ion site, making the enzyme resemble $p d$ PTE. These eight mutations, located in outer co-ordination shells, appear to result in a loss of co-ordination strength because they destabilize the $\beta$-metal ion ligands in the first co-ordination shell; similar differences are also seen between the native arPTE and $p d$ PTE orthologues. The present study demonstrates that evolution can easily (and drastically) alter and fine-tune the metal ion co-ordination strength of enzymes through subtle modification of interactions remote from the metal ion binding sites.

\section{AUTHOR CONTRIBUTION}

Jee-Loon Foo, Colin Jackson and David Ollis designed the research; Jee-Loon Foo, Colin Jackson, Paul Carr and Hye-Kyung Kim performed the research; Jee-Loon Foo, Colin Jackson, Paul Carr, Gerhard Schenk, Lawrence Gahan and David Ollis analysed data; and Jee-Loon Foo, Colin Jackson and David Ollis wrote the paper.

\section{ACKNOWLEDGEMENTS}

We thank the staff at the Stanford Synchrotron Radiation Laboratory for their help with data collection.

\section{FUNDING}

This work was supported by a grant from the Australian Research Council [grant number DP0986613]

\section{REFERENCES}

1 Waldron, K. J. and Robinson, N. J. (2009) How do bacterial cells ensure that metalloproteins get the correct metal? Nat. Rev. Microbiol. 7, 25-35

2 Glusker, J. P. (1991) Structural aspects of metal liganding to functional groups in proteins. Adv. Protein Chem. 42, 1-76

3 Garner, C. D., Collison, D. and Pidcock, E. (1996) The nature of the coordination sites of transition metals in proteins. Philos. Trans. R. Soc. A. 354, 325-357

4 Vipond, I. B., Moon, B. J. and Halford, S. E. (1996) An isoleucine to leucine mutation that switches the cofactor requirement of the EcoRV restriction endonuclease from magnesium to manganese. Biochemistry $35,1712-1721$

5 McLoughlin, S. Y., Jackson, C., Liu, J. W. and Ollis, D. L. (2004) Growth of Escherichia coli coexpressing phosphotriesterase and glycerophosphodiester phosphodiesterase, using paraoxon as the sole phosphorus source. Appl. Environ. Microbiol. 70, 404-412

6 Jackson, C. J., Carr, P. D., Liu, J. W., Watt, S. J., Beck, J. L. and Ollis, D. L. (2007) The structure and function of a novel glycerophosphodiesterase from Enterobacter aerogenes. J. Mol. Biol. 367, 1047-1062

7 Hadler, K. S., Mitic, N., Ely, F., Hanson, G. R., Gahan, L. R., Larrabee, J. A., Ollis, D. L. and Schenk, G. (2009) Structural flexibility enhances the reactivity of the bioremediator glycerophosphodiesterase by fine-tuning its mechanism of hydrolysis. J. Am. Chem. Soc. 131, 11900-11908

8 Leblanc, L., Bennet, A. and Borgford, T. (2000) Calcium affinity of regulatory sites in skeletal troponin-C is attenuated by $\mathrm{N}$-cap mutations of helix C. Arch. Biochem. Biophys. 384, 296-304

9 Trigo-Gonzalez, G., Awang, G., Racher, K., Neden, K. and Borgford, T. (1993) Helix variants of troponin $C$ with tailored calcium affinities. Biochemistry 32, 9826-9831

10 Horne, I., Sutherland, T. D., Harcourt, R. L., Russell, R. J. and Oakeshott, J. G. (2002) Identification of an opd (organophosphate degradation) gene in an agrobacterium isolate. Appl. Environ. Microbiol. 68, 3371-3376

11 Mulbry, W. W. and Karns, J. S. (1989) Parathion hydrolase specified by the flavobacterium opd gene: relationship between the gene and protein. J. Bacteriol. 171, 6740-6746
12 Yang, H., Carr, P. D., McLoughlin, S. Y., Liu, J. W., Horne, I., Qiu, X., Jeffries, C. M. J., Russell, R. J., Oakeshott, J. G. and Ollis, D. L. (2003) Evolution of an organophosphate-degrading enzyme: a comparison of natural and directed evolution. Protein Eng. 16, 135-145

13 Caldwell, S. R., Newcomb, J. R., Schlecht, K. A. and Raushel, F. M. (1991) Limits of diffusion in the hydrolysis of substrates by the phosphotriesterase from Pseudomonas diminuta. Biochemistry 30, 7438-7444

14 Jackson, C. J., Foo, J. L., Tokuriki, N., Afriat, L., Carr, P. D., Kim, H. K., Schenk, G., Tawfik, D. S. and Ollis, D. L. (2009) Conformational sampling, catalysis, and evolution of the bacterial phosphotriesterase. Proc. Natl. Acad. Sci. U.S.A. 106, 21631-21636

15 Ely, F., Foo, J.-L., Jackson, C. J., Gahan, L. R., Ollis, D. and Schenk, G. (2007) Enzymatic bioremediation: organophosphate degradation by binuclear metallo-hydrolases. Curr. Top. Biochem. Res. 9, 63-78

16 Jackson, C. J., Weir, K., Herlt, A., Khurana, J., Sutherland, T. D., Horne, I., Easton, C., Russell, R. J., Scott, C. and Oakeshott, J. G. (2009) Structure-based rational design of a phosphotriesterase. Appl. Environ. Microbiol. 75, 5153-5156

17 Dumas, D. P., Durst, H. D., Landis, W. G., Raushel, F. M. and Wild, J. R. (1990) Inactivation of organophosphorus nerve agents by the phosphotriesterase from Pseudomonas diminuta. Arch. Biochem. Biophys. 277, 155-159

18 Kolakowski, J. E., Defrank, J. J., Harvey, S. P., Szafraniec, L. L., Beaudry, W. T., Lai, K. and Wild, J. R. (1997) Enzymic hydrolysis of the chemical warfare agent VX and its neurotoxic analogs by organophosphorus hydrolase. Biocatal. Biotransform. 15, 297-312

19 Rastogi, V. K., Defrank, J. J., Cheng, T. C. and Wild, J. R. (1997) Enzymic hydrolysis of Russian-VX by organophosphorus hydrolase. Biochem. Biophys. Res. Commun. 241, 294-296

20 diSioudi, B., Grimsley, J. K., Lai, K. and Wild, J. R. (1999) Modification of near active site residues in organophosphorus hydrolase reduces metal stoichiometry and alters substrate specificity. Biochemistry 38, 2866-2872

21 Li, W. S., Lum, K. T., Chen-Goodspeed, M., Sogorb, M. A. and Raushel, F. M. (2001) Stereoselective detoxification of chiral sarin and soman analogues by phosphotriesterase. Bioorg. Med. Chem. 9, 2083-2091

22 Benning, M. M., Kuo, J. M., Raushel, F. M. and Holden, H. M. (1995) Three-dimensional structure of the binuclear metal center of phosphotriesterase. Biochemistry $\mathbf{3 4}$, 7973-7978

23 Dumas, D. P., Caldwell, S. R., Wild, J. R. and Raushel, F. M. (1989) Purification and properties of the phosphotriesterase from Pseudomonas diminuta. J. Biol. Chem. 264 , 19659-19665

24 Jackson, C. J., Carr, P. D., Kim, H. K., Liu, J. W., Herrald, P., Mitic, N., Schenk, G., Smith, C. A. and Ollis, D. L. (2006) Anomalous scattering analysis of Agrobacterium radiobacter phosphotriesterase: the prominent role of iron in the heterobinuclear active site. Biochem. J. 397, 501-508

25 Omburo, G. A., Kuo, J. M., Mullins, L. S. and Raushel, F. M. (1992) Characterization of the zinc binding site of bacterial phosphotriesterase. J. Biol. Chem. 267, 13278-13283

26 Benning, M. M., Shim, H., Raushel, F. M. and Holden, H. M. (2001) High resolution X-ray structures of different metal-substituted forms of phosphotriesterase from Pseudomonas diminuta. Biochemistry 40, 2712-2722

27 Shim, H. and Raushel, F. M. (2000) Self-assembly of the binuclear metal center of phosphotriesterase. Biochemistry 39, 7357-7364

28 Aubert, S. D., Li, Y. and Raushel, F. M. (2004) Mechanism for the hydrolysis of organophosphates by the bacterial phosphotriesterase. Biochemistry 43, 5707-5715

29 Hong, S. B. and Raushel, F. M. (1996) Metal-substrate interactions facilitate the catalytic activity of the bacterial phosphotriesterase. Biochemistry 35, 10904-10912

30 Kuo, J. M., Chae, M. Y. and Raushel, F. M. (1997) Perturbations to the active site of phosphotriesterase. Biochemistry 36, 1982-1988

31 Emsley, P. and Cowtan, K. (2004) Coot: model-building tools for molecular graphics. Acta Crystallogr. D. 60, 2126-2132

32 Jackson, C., Kim, H. K., Carr, P. D., Liu, J. W. and Ollis, D. L. (2005) The structure of an enzyme-product complex reveals the critical role of a terminal hydroxide nucleophile in the bacterial phosphotriesterase mechanism. Biochim. Biophys. Acta 1752, 56-64

33 Collaborative Computational Project, Number 4 (1994) The CCP4 suite: programs for protein crystallography. Acta Crystallogr. Sect. D Biol. Crystallogr. 50, 760-763

34 Reference deleted

35 Roodveldt, C. and Tawfik, D. S. (2005) Directed evolution of phosphotriesterase from Pseudomonas diminuta for heterologous expression in Escherichia coli results in stabilization of the metal-free state. Protein Eng. Des. Sel. 18, 51-58

36 McLoughlin, S. Y., Jackson, C., Liu, J. W. and Ollis, D. (2005) Increased expression of a bacterial phosphotriesterase in Escherichia coli through directed evolution. Protein Expression Purif. 41, 433-440 
37 Chen-Goodspeed, M., Sogorb, M. A., Wu, F. and Raushel, F. M. (2001) Enhancement, relaxation, and reversal of the stereoselectivity for phosphotriesterase by rational evolution of active site residues. Biochemistry 40, 1332-1339

38 Rulisek, L. and Vondrasek, J. (1998) Coordination geometries of selected transition metal ions $\left(\mathrm{Co}^{2+}, \mathrm{Ni}^{2+}, \mathrm{Cu}^{2+}, \mathrm{Zn}^{2+}, \mathrm{Cd}^{2+}\right.$, and $\left.\mathrm{Hg}^{2+}\right)$ in metalloproteins. J. Inorg. Biochem. 71, 115-127

39 Auld, D. S. (2001) Zinc coordination sphere in biochemical zinc sites. Biometals $\mathbf{1 4}$, $271-313$

40 Dudev, T., Lin, Y. L., Dudev, M. and Lim, C. (2003) First-second shell interactions in metal binding sites in proteins: a PDB survey and DFT/CDM calculations. J. Am. Chem. Soc. 125, 3168-3180

41 Gervasio, F. L., Schettino, V., Mangani, S., Krack, M., Carloni, P. and Parrinello, M. (2003) Influence of outer-shell metal ligands on the structural and electronic properties of horse liver alcohol dehydrogenase zinc active site. J. Phys. Chem. B 107, 6886-6892

Received 10 February 2010/7 May 2010; accepted 11 May 2010

Published as BJ Immediate Publication 11 May 2010, doi:10.1042/BJ20100233
42 DiTusa, C. A., McCall, K. A., Christensen, T., Mahapatro, M., Fierke, C. A. and Toone, E. J. (2001) Thermodynamics of metal ion binding. 2: Metal ion binding by carbonic anhydrase variants. Biochemistry 40, 5345-5351

43 Kiefer, L. L., Paterno, S. A. and Fierke, C. A. (1995) Hydrogen-bond network in the metal-binding site of carbonic-anhydrase enhances zinc affinity and catalytic efficiency. J. Am. Chem. Soc. 117, 6831-6837

44 Marino, S. F. and Regan, L. (1999) Secondary ligands enhance affinity at a designed metal-binding site. Chem. Biol. 6, 649-655

45 Karlin, S., Zhu, Z. Y. and Karlin, K. D. (1997) The extended environment of mononuclear metal centers in protein structures. Proc. Natl. Acad. Sci. U.S.A. 94, 14225-14230

46 Yang, C. M., Li, X. Y., Wei, W., Li, Y. T., Duan, Z. J., Zheng, J. Y. and Huang, T. (2007) Dissecting the general physicochemical properties of noncovalent interactions involving tyrosine side chain as a second-shell ligand in biomolecular metal-binding site mimetics: an experimental study combining fluorescence, ${ }^{13} \mathrm{C}$-NMR spectroscopy and ESI mass spectrometry. Chem. Eur. J. 13, 3120-3130 


\title{
SUPPLEMENTARY ONLINE DATA \\ Mutation of outer-shell residues modulates metal ion co-ordination strength in a metalloenzyme
}

\author{
Jee-Loon F00*, Colin J. JACKSON†, Paul D. CARR ${ }^{\star}$, Hye-Kyung KIM* , Gerhard SCHENK $\ddagger$, Lawrence R. GAHAN $\ddagger$ and \\ David L. OLLIS*1 \\ *Research School of Chemistry, Australian National University, Australian Capital Territory 0200, Australia, † Institut de Biologie Structurale, Centre National de la Recherche \\ Scientifique, Grenoble 38027, France, and $¥$ School of Chemistry and Molecular Biosciences, University of Queensland, St Lucia, Queensland 4072, Australia
}

\section{METHODS}

\section{Strains, plasmids and chemicals}

arPTE and $p d$ PTE were expressed from expression vectors pETMCSI and pCY76 [1] respectively, carrying the corresponding genes. The plasmid of arPTE $8 \mathrm{M}$ was isolated through directed evolution as described previously [2]. The restriction sites were NdeI and EcoRI. Escherichia coli DH5 $\alpha$ and BL21(DE3) ${ }^{\text {RecA }-}$ strains were used in the present study. Paraoxon (EPO) and diethyl phosphate were purchased from Chem Service. EPO-OMe (diethyl 4-methoxyphenyl phosphate) was synthesized as described previously [3]. Molecular biology reagents were purchased from New England Biolabs or Roche unless otherwise stated. Other chemicals were procured from Sigma-Aldrich. Plasmid DNA was purified using mini-prep kits (Qiagen). Oligonucleotide primers were synthesized by Geneworks.

\section{Construction of single-site mutants}

The mutations of S203A, S205A, Q206A and Q206P for arPTE, and $\mathrm{H} 254 \mathrm{R}$ for $p d \mathrm{PTE}$ were constructed from the corresponding genes of wild-type arPTE in pETMCSI and $p d$ PTE in pCY76 using the QuikChange ${ }^{\circledR}$ (Stratagene) protocol. The PCR mixtures consisted of $20 \mathrm{ng}$ of DNA template, $200 \mu \mathrm{M}$ dNTP, 1 unit of Phusion DNA polymerase (Finnzyme), $0.2 \mu \mathrm{M}$ mutagenic primers and $10 \mu \mathrm{l}$ of $5 \times$ Phusion reaction buffer, made up to $50 \mu \mathrm{l}$ with deionized water. The reaction mixture was subjected to an initial denaturation at $98^{\circ} \mathrm{C}$ for $1 \mathrm{~min}$, followed by 25 cycles of $98^{\circ} \mathrm{C}$ for $10 \mathrm{~s}, 65^{\circ} \mathrm{C}$ for $30 \mathrm{~s}$ and $72^{\circ} \mathrm{C}$ for $90 \mathrm{~s}$ (or $60 \mathrm{~s}$ for pCY76). The PCR mixture was digested with DpnI at $37^{\circ} \mathrm{C}$ for $3 \mathrm{~h}$

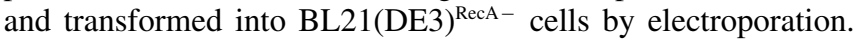
Plasmids were isolated with miniprep kits and sequenced.

\section{PTE purification}

BL21(DE3) RecA - cells were transformed with wild-type and arPTE 8M-encoding genes in pETMCSI vector and pCY76pdPTE plasmid by electroporation. Cells were grown on a Luria-Bertani broth agar plate (supplemented with $100 \mu \mathrm{g} / \mathrm{ml}$ ampicillin) at $37^{\circ} \mathrm{C}$ overnight. For kinetic assays, a single colony was inoculated into $10 \mathrm{ml}$ of Terrific broth medium supplemented with $1 \mathrm{mM} \mathrm{CoCl}{ }_{2}$ and $100 \mu \mathrm{g} / \mathrm{ml}$ ampicillin and incubated at $37^{\circ} \mathrm{C}$ for $8 \mathrm{~h}$. The culture was then transferred into $400 \mathrm{ml}$ of the same medium and grown at $37^{\circ} \mathrm{C}$ for $40 \mathrm{~h}$. Cells were harvested at $6000 \mathrm{~g}$ for $20 \mathrm{~min}$ at $4{ }^{\circ} \mathrm{C}$ and resuspended in $50 \mathrm{ml}$ of $50 \mathrm{mM}$ Hepes (pH 8.0) with $1 \mathrm{mM} \mathrm{CoCl}$. The cells were lysed with a French Press and the lysate was centrifuged at $30000 \mathrm{~g}$ for $40 \mathrm{~min}$
Table S1 Data collection and refinement statistics for arPTE 8M structures

Results are from [2]. Crystals of arPTE $8 \mathrm{M}$ were stored in metal-ion-free cryoprotecting solution for $12 \mathrm{~h}$ (PDB code 3A3X) and $72 \mathrm{~h}$ (PDB code 3A3W) prior to data collection. Values in parentheses are for the highest-resolution shell. $R_{\text {symm }}=\Sigma_{h k l} \Sigma_{i}\left|l_{i}(h k l)-<\right|(h k l)>\mid / \Sigma_{h k l} \Sigma_{i}$ $\mathrm{l}_{i}(h k l)$ where $I(h k l)$ is the average intensity of $/$ symmetry-related observations of reflections with Miller indices $h k \mid$. $R_{\text {work }}=\Sigma_{h k l}\left|F_{0}-F_{c}\right| / \Sigma_{h k l}\left|F_{0}\right| ; 5 \%$ of the data that were excluded from the refinement were used to calculate $R_{\text {free }}$. Rmsd, root-mean-square deviation.

\begin{tabular}{|c|c|c|}
\hline Parameter & PDB code 3A3W & PDB code 3A3X \\
\hline Space group & $P 3,21$ & $P 3,21$ \\
\hline Unit cell parameters $(\AA)$ & $a=109.01, c=62.69$ & $a=109.16, c=62.69$ \\
\hline \multicolumn{3}{|l|}{ Data collection } \\
\hline Resolution $(\AA)$ & $40-1.70(1.76-1.70)$ & $40.0-1.70(1.76-1.70)$ \\
\hline Unique reflections & 43843 & 47531 \\
\hline Redundancy & $9.5(3.1)$ & $10.3(7.4)$ \\
\hline $1 / \sigma(I)$ & $25.5(1.7)$ & $39.9(6.0)$ \\
\hline Completeness (\%) & $92.4(51.9)$ & $99.9(99.1)$ \\
\hline$R_{\text {summ }}(\%)$ & $7.8(40.6)$ & $5.3(24.7)$ \\
\hline \multicolumn{3}{|l|}{ Refinement } \\
\hline No. reflections work/free & $34885 / 1715$ & $45190 / 2316$ \\
\hline Resolution range & $29.8-1.85(1.90-1.85)$ & $40.0-1.70(1.74-1.70)$ \\
\hline$R_{\text {work }} / R_{\text {free }}(\%)$ & $17.4 / 20.9(25.9 / 33.9)$ & $17.6 / 19.6(22.7 / 28.0)$ \\
\hline \multicolumn{3}{|l|}{ Rmsd } \\
\hline Lengths $(\AA ̊)$ & 0.017 & 0.11 \\
\hline Angles $\left(^{\circ}\right)$ & 1.62 & 1.43 \\
\hline
\end{tabular}

at $4{ }^{\circ} \mathrm{C}$ to separate the cell debris. The supernatant was loaded on to a $5 \mathrm{ml}$ HiTrap DEAE FF (GE Healthcare) column and the eluate was collected followed by dialysis against $50 \mathrm{mM}$ Hepes, $\mathrm{pH} 7.0$, overnight. The protein was loaded on to a $5 \mathrm{ml}$ HiTrap SP FF (GE Healthcare) column equilibrated with $50 \mathrm{mM}$ Hepes, $\mathrm{pH}$ 7.0, and bound arPTE was eluted using a linear gradient from 0 to $0.5 \mathrm{M}$. The protein was dialysed against $50 \mathrm{mM}$ Hepes, $\mathrm{pH} 7.0$, containing $1 \mathrm{mM} \mathrm{CoCl}_{2}$ and $150 \mathrm{mM} \mathrm{NaCl}$.

\section{REFERENCES}

1 Yang, H., Carr, P. D., McLoughlin, S. Y., Liu, J. W., Horne, I., Qiu, X., Jeffries, C. M. J., Russell, R. J., Oakeshott, J. G. and Ollis, D. L. (2003) Evolution of an organophosphate-degrading enzyme: a comparison of natural and directed evolution. Protein Eng. 16, 135-145

2 Jackson, C. J., Foo, J. L., Tokuriki, N., Afriat, L., Carr, P. D., Kim, H. K., Schenk, G., Tawfik, D. S. and Ollis, D. L. (2009) Conformational sampling, catalysis, and evolution of the bacterial phosphotriesterase. Proc. Natl. Acad. Sci. U.S.A. 106, 21631-21636

3 Jackson, C. J., Foo, J. L., Kim, H. K., Carr, P. D., Liu, J. W., Salem, G. and Ollis, D. L. (2008) In crystallo capture of a Michaelis complex and product-binding modes of a bacterial phosphotriesterase. J. Mol. Biol. 375, 1189-1196 